important recommendation in the report is no doubt the call for a 'world weather watch', a global meteorological observing and prediction system designed to avoid duplication of effort in the preparation of analysed charts and forecasts, yet providing all meteorological services with the basic data needed to carry out their responsibilities. The report also proposes that the scope and quality of both conventional and satellite observations should be improved and emphasizes that the latter supplement but do not supplant the former. Optimum results can be achieved by means of a combination of the wide scanning ability of the satellites with the capabilities of the usual vertical sounding instruments. Improvements should also be made to the communication facilities to permit the rapid trans- mission of a greatly increased volume of meteorological traffic throughout the world. The hope is expressed that the satellites themselves may serve as communication systems for this purpose.

The evaluation of the optimum utilization of meteorological satellites is an important issue that must be faced. The United Nations and its specialized agency, the World Meteorological Organization, have taken a big step forward. The working group which has been established to formulate an atmospheric sciences programme will keep the matter under active review until the World Meteorological Organization Congress constitutes an advisory committee at its fourth session in April 1963. There is a long road to tread before the full potential of meteorological satellites will come to fruition. A. H. GorDON

\title{
FILARIASIS
}

$\mathrm{D}$ URING the past few years, filariasis control has progressed to the point where it has become possible to look forward to the introduction of eradication campaigns like that organized by the World Health Organization for malaria. In contrast to the malaria programmes, however, the first line of attack would have to be mass chemotherapy, mainly because of the long life of the parasite in the human body. To keep transmission at a low enough level to ensure eradication, chemotherapy will have to be backed up by adequate vector control. This may not prove easy, since the culicine mosquitoes, the main vectors of filariasis, rapidly acquire resist. ance to the commonly used insecticides and since the habitats of some of the mosquitoes make it difficult to attack them by conventional methods.

The World Health Organization Expert Committeo on Filariasis has reviewed recent advances in the epidemiology of Wuchereria and Brugia infections and directed attention to the many problems on which research is still needed*. It is important to improve methods of identifying developing forms of filariæ in mosquitoes, so that carriers of animal filariæ should not be mistaken for vectors of the

* World Health Organization. Technical Report Series. No. 233 : Expert Committee on Filariasis (Wuchereria and Brugia Infections) H.M. Stationery Office, 1962). 2 Swiss franes ; $3 s .6 d . ; 0.60$ dollars. human infection. Expert taxonomic, $\theta$ cological and other studies are needed to establish the strains with the highest infective potential and the most effective means of destroying them. Rapid urbanization has enabled Culex fatigans to breed apace in some areas with only primitive sanitation, and the situation has been made worse where insecticide spraying campaigns for malaria eradication have eliminated competitors of this mosquito. The Committee recommends that, wherever possible, Culex fatigans should be attacked by improvements in sanitation aimed at suppressing man-made breeding sites.

Diethylcarbamazine appears to be still the most satisfactory drug available for mass chomotherapy, but a number of new compounds containing arsenic or antimony are at present under trial. Further research is needed to establish the best dosage schedule for diethylcarbamazine- one that, in order to ensure a high acceptability, combines effectiveness with ease of administration and relative freedom from side-effects.

Among the other subjects suggested for research. the Committee advocates studies on transmission and on the life-cycle of the parasite in relation to clinical manifestations, serological and immunological studies on filariasis, and an investigation of the effect of malaria eradication activities on the local epidemiology of filariasis.

\section{INHERITANCE IN BACTERIA}

\begin{abstract}
MONG the wide variety of research activities described in the report of the Governing Body of the Lister Institute of Preventive Medicine for $1962 *$, that of the investigations of the GuinessLister Unit into inheritance in bacteria is of particular interest. The Unit continued its investigation of inheritance in bacteria of the Salmonella (food poisoning and enteric fever) groups, using two different kinds of fertility factor to induce conjugation: the colicine factors, which determine the production of antibiotics called colicines, and the $F$ factor and some variants of it, transferred from Escherichia coli.
\end{abstract}

* The Lister Institute of Preventive Medicine. Report of the Governing Body 1962. Pp. 29. (London: The Lister Institute of Preventive Medicine, 1962).
S. Smith continued to map the chromosome of Salmonella typhimurium, obtaining conjugation (and hybridization) by the use of colicine factors col $I$ and col EI. Additional hereditary characters were introduced into the strains used, by the isolation of mutants unable to synthesize particular amino-acids, to ferment particular sugars or to produce the fraction of the polysaccharide component of the $O$ antigen factor 5. Many of these mutants were obtained by treating bacteria with the mutagen ethyl methane sulphonate. The genes regulating all the characters concerned were mapped in the single closed-loop linkage map already tentatively established. Dr. B. A. D. Stocker, E. Subbaiah, and E. Dubnau, using the same system, investigated the segregation of additional characters resulting from 
mutation in the laboratory or pre-existing in strains isolated from natural sources.

From analogy with the situation in mating of Escherichia coli resulting from activity of the fertility factor $F$, it was suspected that, in conjugation of Salmonella induced by colicine factors, the partner carrying the colicine factor acts as a 'male' and injects a part or perhaps the wholo of its chromosome into the cytoplasm of the other, 'female', partner. Some data on frequency of various recombinant classes cast doubt on this idea, and suggested that perhaps the partner which was lacking the colicine factors sometimos acted as 'male'. S. Smith, in a further investigation of erosses in which a reversal of sexual roles was suspected, has now shown that if in such a cross the partner carrying the colicine factors is resistant to streptomycin and the other partner sensitive, exposure to streptomycin prevents the appearance of nearly all the streptomycin-resistant recombinants which develop in the absence of the antibiotic. This is the result expected if only the colicogenic partner can inject its chromosome into its partner; for sensitive 'female' bacteria which had received a chromosome fragment from the streptomycin-resistant colicinogenic partner would be killed by the antibiotic, even when the injected chromosome fragment carried the gene for resistance to streptomycin, because of the streptomycin-sensitivity of their own cytoplasm.

Subbaiah and Stocker established that two genes, regulating, respectively, ability to ferment rhamnose and ability to produce the filamentous bacterial appendages, called fimbrix, are well separated in the chromosome and functionally independent, despite the almost complete correlation of the two characters in 'wild' strains of Salmonella typhimurium. Now that the chromosome of Salmonella typhimurium has been reasonably well mapped, new investigations of the genetics of virulence in this species have been begun by Subbaiah. As a start he has isolated a series of 'rough' mutants, in strain $L T 2$, as the 'rough' character entails loss of virulence.

\title{
GROWTH OF A CLONED STRAIN OF HAMSTER KIDNEY CELLS IN SUSPENDED CULTURES AND THEIR SUSCEPTIBILITY TO THE VIRUS OF FOOT-AND-MOUTH DISEASE
}

\author{
By P. B. CAPSTICK, R. C. TELLING, W. G. CHAPMAN and DOREEN L. STEWART \\ Research Institute (Animal Virus Diseases), Pirbright
}

$\mathrm{M}$ ACPHERSON and Stoker ${ }^{1}$ have described the origin of the baby hamster kidney cell strain 21 $(B H K 21)$, and Mowat and Chapman ${ }^{2}$ the susceptibility of the strain to the virus of foot-and-mouth disease $(F M D)$ in monolayer cultures. All experiments so far reported with this cell strain have utilized cells grown in monolayer cultures. The advantages of suspended cell culture techniques are obvious if the cell is to be used for large-scale vaccine production or even for extensive laboratory use in plaque assay systems. The experiments described here demonstrate the growth of a cloned strain of these cells (clone 13) in suspended cell eulture.

Culture of colls in suspension was carried out in cylindrical 'Pyrex' glass vessels, 3 in. in diameter, $10 \mathrm{in.}$ in height, with two glass entry ports in the top end. The volume of culture used was $200 \mathrm{ml}$., which occupied about one-third of the vessels. The cultures were stirred by central 'Teflon'-coated bar magnets rotated at 335 r.p.m. by mechanically propelled external magnets. The vessels were held in a $37^{\circ} \mathrm{C}$ copper water bath. They were sealed with glass stoppers after seeding and no aeration was attempted. Slight gas exchange with the atmosphere occurred when the cultures were sampled.

The medium consisted of Eagle's basal medium modified to contain twice the normal concentration of amino-acids and vitamins with 10 per cent Seitzfiltered bovine serum and 10 per cent tryptose phosphate broth. Antibiotics were incorporated to final concentrations per ml. of 100 units penicillin and streptomycin, 25 units mycostatin, and 70 units neomycin.

$B H K 21$ clone 13 cells which had had 110 monolayer transfers were suspended in the foregoing medium and added to the vessels, the contents of which were collected every 2 days or when the cell concentration in the vessels ceased to increase. During the first 21 days in culture, growth was irregular with considerable clumping of cells and growth on the sides of the vessels. This was counteracted by collecting the cells every $24 \mathrm{~h}$ and resuspending them in 'Versene'-trypsin $(0.01$ per cent) mixture in the vessels for $l h$. The 'Versene'-trypsin was then removed and fresh medium substituted. After this initial period, regular growth occurred and we were able to collect cells from the vessels every $48 \mathrm{~h}$ with a constant cell yield of 2 to $3 \cdot 6 \times 10^{8 \cdot 0}$ cells per vessel. Cell clumping was still a problem although there was little growth on the sides of vessels that had been in use for six days or more. Better assessments of the number of cells in a vessel were obtained by collecting the contents and subjecting both cells and vessel to the 'Versene'-trypsin treatmont described above.

The results of a typical growth-cycle are shown in Fig. 1, from which it can be seen that from a seed of $3.5 \times 10^{5.0}$ cells per ml. a final concentration of 1.65 $\times 10^{6 \cdot 0}$ per $\mathrm{ml}$. was achieved in $40 \mathrm{~h}$. This figure also demonstrates that the growth-curve was linear in character, and this is presumptive evidence that a rate-limiting factor or factors was operating. Further investigations on the nature of these limiting factors is being carried out.

The work of Hayflick and Moorhead ${ }^{3}$ on human diploid cell strains suggests that, to achieve successful growth in suspended culture, a diploid cell strain must change its chromosome karyotype from diploir to heteroploid and that a change may occur in the range of viruses to which the cell is susceptible. Wo have not yet observed these changes with $B H K 21$ 